\title{
EDUCAÇÃO INCLUSIVA COMO ESTRATÉGIA ANALÍTICA
}

\author{
LA EDUCACIÓN INCLUSIVA COMO ESTRATEGIA ANALÍTICA ${ }^{1}$
}

INCLUSIVE EDUCATION AS ANALYTICAL STRATEGY

Aldo OCAMPO GONZÁLEZ ${ }^{2}$

RESUMO: O presente trabalho expõe uma proposta crítica para transformar a estrutura de conhecimento existente, ao mesmo tempo em que transforma a realidade e a consciência de seus atores - o princípio da audibilidade. Avanços na construção e / ou produção diferenciada de conhecimentos educacionais, reconfigurando suas linguagens, estruturas e engenharia educacionais. Propõe-se desvendar uma variedade de estruturas de conhecimento que contribuem para a reprodução imperceptível de uma ampla variedade de expressões de poder, bem como projetos de conhecimento cúmplices com desigualdade, opressão e dominação. A inclusão como método apresenta uma abordagem analítica única, distancia-se de um conjunto de abordagens que concebem a seção da frase referente ao "método" como uma técnica ou metodologia específica. Em vez disso, apresenta a fabricação de uma estratégia epistemológica para abordar uma ampla variedade de problemas educacionais complexos. Num segundo momento, analisa as possibilidades de inclusão como uma teoria pósdisciplinar, não fixada em nenhuma disciplina. A natureza de seu gênero é explorada demonstrando que seu objeto de trabalho de educação inclusiva impõe 'outro lugar', ou seja, ao constituir um fenômeno pós-disciplinar, forma um gênero singular em sua constituição. É convergido analisando o potencial heurístico da cidade ou o que habita entre os dois termos configuradores da frase. A 'y-cidad' é a chave para entender o espaço da diáspora, transborda o sistema programático convencional, explicitamente re-cognitivo, opera como um espaço de intersticialidade.

PALAVRAS-CHAVE: Epistemologia da educação inclusiva. Y-cidad. Inclusão como método. Género. Poder heurístico.

RESUMEN: El presente trabajo expone una propuesta crítica para transformar la estructura de conocimiento existente de la educación inclusiva, al mismo tiempo, transforma la realidad y las consciencias de sus actores -principio de audibilidad-. Avanza en la construcción y/o producción diferente del conocimiento educativo, reconfigurando sus lenguajes, estructuras e ingenierías educativas. Se propone des-enredar una variedad de estructuras de conocimiento que contribuyen a la reproducción imperceptible de una amplia variedad de expresiones del poder, así como, proyectos de conocimiento cómplices con la desigualdad, la opresión y la

1 Conferencia impartida por invitación el día viernes 22 de noviembre de 2019 en el XIV Encuentro Internacional de Educación (EIDE), Eje: Conocimientos de la Educación Inclusiva, organizado por UNESP, Araraquara, Brasil.

${ }^{2}$ Centro de Estudios Latinoamericanos de Educación Inclusiva (CELEI), Santiago de Chile, Chile. Director fundador CELEI, Depto. Teoría y metodología de la Educación Inclusiva. Doctor en Ciencias de la Educación, aprobado Sobresaliente mención 'Cum Laude', por la Universidad de Granada, España. ORCID: https://orcid.org/0000-0002-6654-8269. E-mail: aldo.ocampo.gonzalez@gmail.com 
dominación. Inclusión como método presenta un singular enfoque analítico, se distancia de un conjunto de planteamientos que conciben la sección del sintagma referida al 'método' en tanto técnica o metodología en particular. Más bien, presenta la fabricación de una estrategia epistemológica para abordar una amplia variedad de problemas educativos de carácter complejos. En un segundo momento, analiza las posibilidades de la inclusión en tanto teoría post-disciplinar, no fija en ninguna disciplina. Se explora la naturaleza de su género demostrando que su objeto de trabajo de la educación inclusiva impone 'otro lugar', es decir, al constituir un fenómeno de carácter post-disciplinar, forma un género singular en su constitución. Se confluye analizando el potencial heurístico de la y-cidad o aquello que habita entre ambos términos configurantes del sintagma. La 'y-cidad' es clave para comprender el espacio de diáspora, desborda las programaticidades convencionales, explicita un sistema re-cognoscitivo, opera como un espacio de intersticialidad.

PALABRAS CLAVE: Epistemología de la educación inclusiva. Y-cidad. Inclusión como método. Género. Poder heurístico.

ABSTRACT: The present work exposes a critical proposal to transform the existing knowledge structure of inclusive education, at the same time; it transforms the reality and the consciences of its actors - the principle of audibility. Advances in the construction and / or different production of educational knowledge, reconfiguring their educational languages, structures and engineering. It is proposed to unravel a variety of knowledge structures that contribute to the imperceptible reproduction of a wide variety of expressions of power, as well as, complicit knowledge projects with inequality, oppression and domination. Inclusion as a method presents a unique analytical approach, it distances itself from a set of approaches that conceive the section of the phrase referring to the 'method' as a particular technique or methodology. Rather, it presents the fabrication of an epistemological strategy to address a wide variety of complex educational problems. In a second moment, it analyzes the possibilities of inclusion as a post-disciplinary theory, not fixed in any discipline. The nature of their gender is explored by demonstrating that their work object of inclusive education imposes 'another place', that is, by constituting a post-disciplinary phenomenon, it forms a singular gender in its constitution. It is converged by analyzing the heuristic potential of the city or that which inhabits between the two configuring terms of the phrase. The 'ycidad' is key to understanding the diaspora space, overflows with conventional programmatic, explicitly re-cognitive system, operates as a space of interstitiality.

KEYWORDS: Epistemology of inclusive education. Y-cidad. Inclusion as a method. Gender. Heuristic power.

\section{Introducción: inclusión como método}

Inclusión como método presenta un singular enfoque analítico, se distancia de un conjunto de planteamientos que conciben la sección del sintagma referida al 'método' en tanto técnica o metodología en particular. Más bien, presenta la fabricación de una estrategia epistemológica para abordar una amplia variedad de problemas educativos de carácter complejos. La sección referida al 'método' configura una estrategia analítica y reflexiva 
destinada a examinar problemas y cuestiones que surgen de nuestras experiencias en la multiplicidad de microprácticas -herederas y reproductoras de una amplia variedad de microopresiones y micro-dominaciones- entrecruzadas que ensamblan el sistema-mundo. $\mathrm{Su}$ heurística trabaja a partir de la metáfora post-colonial 'hablar de vuelta' que, a juicio de Smith (1999), configura un nuevo vocabulario y un sistema recognoscitivo dedicado a comprender una multiplicidad de problemáticas. La analítica que configura 'inclusión como método' puede asemejarse a lo que Mezzadra y Neilson (2012) denominan un nuevo continente de posibilidades políticas, éticas y epistemológicas, cuya espacialidad analítica e intensas preocupaciones e intereses, no responden a las lógicas de formalización de los métodos establecidos. Crea nuevas formas de lectura y mediación de los fenómenos que constituyen su campo de producción, análisis y lucha política. Forja una praxis crítica de examinación de la realidad, así como, de los principales proyectos de conocimiento que crean y garantizan la producción del conocimiento de la educación inclusiva. Es una analítica inquieta que no se cierra, ni detiene en los formalismos lógicos de ninguno de los repertorios metodológicos legados por las Ciencias Sociales. Es, también, un singular umbral analítico. La inclusión es, en sí misma, un dispositivo de transformación de la estructura de producción del conocimiento de la Ciencia Educativa en su conjunto. A este complejo proceso, en trabajos anteriores, he denominado dispositivo macro-educativo, que en sí mismo, es un sistema de recognición de la teoría educativa contemporánea.

El estudio de las condiciones de producción de la educación inclusiva oscila entre una dimensión extra e intra-teórica. Coincidiendo con Chen (2010), las condiciones de producción ${ }^{3}$ son, en cierta medida, espacios imperceptibles de operación del colonialismo y del capitalismo, así como, del poder, específicamente, en fenómenos ambivalentes como el aquí analizado, que surge de complejos enredos genealógicos, así como, de la rearticulación de condiciones de producción de carácter extra e intra-teóricas. Las primeras, corresponden al corpus de fenómenos sociales que contribuyen a la modelización de un campo de investigación, mientras que, las segundas, refieren a condiciones esencialmente, especulativas y analíticas. El estado actual del campo de educación inclusiva debido a la precariedad de sus sistemas intelectuales e ininteligibilidad de su estatus, específicamente, su déficit epistemológico y metodológico, permite describir su desarrollo en términos de 'fase de descubrimiento'. En este escenario, sus condiciones de producción presentan serias limitaciones estructurales, políticas, éticas y analíticas. Más bien, su campo puede ser descrito

${ }^{3}$ Lugar privilegiado para la articulación de complejas operatorias del poder. 
en términos de tecnología de falsificación, saberes acumulados en la práctica y en la experiencia, no oficializados en una estructura de conocimiento inteligible coherente con su autenticidad epistémica -fracaso cognitivo fundamentado en la imposición de la educación especial-. El estudio de las condiciones de producción de la educación inclusiva emerge mediante una empresa des-estructuradora, orientada a trascender sus limitaciones configuradoras y significantes que desvirtúan su actividad cognitiva, descubre posibilidades alternativas en la reinvención del saber educativo.

La capacidad heurística que contiene la noción de 'educación inclusiva', concibe la sección del sintagma 'inclusiva' como un punto de anclaje que posibilita la transformación de nuestra subjetividad, de allí que, Ocampo (2019) sostenga que ésta, construye un singular estilo de subjetividad. La inclusión es, en sí misma, una propuesta crítica para transformar la estructura de conocimiento existente, al mismo tiempo, transforma la realidad y las consciencias de sus actores - principio de audibilidad ${ }^{4}$-. Avanza en la construcción y/o producción de un conocimiento educativo diferente, reconfigurando sus lenguajes, estructuras e ingenierías educativas. Se propone desenredar una variedad de estructuras de conocimiento que contribuyen a la reproducción imperceptible de una amplia variedad de expresiones del poder, así como, proyectos de conocimiento cómplices con la desigualdad, la opresión y la dominación.

La inclusión como método construye una singular estrategia analítica dedicada a examinar cómo circulan y se transforman las ideas en su viaje por una amplia multiplicidad de marcos teóricos, disciplinas, discursos, geografías y regionalizaciones epistémicas, etc. Esta perspectiva emerge de la metáfora del viaje y del diaspórismo, fomenta la integración de diversos problemas epistémicos, metodológicos, éticos y políticos, mediante la performatividad de lo rearticulatorio, la examinación topológica y la traducción de cada una de sus singularidades intelectuales que confluyen en su red de producción. Dicha red de conexión estriada y multinivel, actúa en términos de lo que Chen (2010) denomina 'imaginación desafiante' o en palabras de Oliveira (2016), 'punto de mutación del pensamiento'. Esta orientación persigue la creación de estrategias creativas de análisis de la realidad e intervención en el sistema-mundo. Inclusión como método es, lo que en el capítulo titulado: "Comprensión epistemológica de la Educación Inclusiva: constelaciones,

\footnotetext{
${ }^{4}$ Para profundizar en torno a las características del adjetivo 'inclusivo', véase el texto: "Incluir: un verbo instransitivo", publicado en la Revista de Estudios Críticos de Arte y Cultura Contemporánea (ÉCFRASIS).
} 
movimientos, encuentros y plasticidades", abordé bajo la denominación kantiana de "medios de orientación en el pensamiento de la educación inclusiva', pues, impone una orientación epistemológica específica, cuyas implicancias confirman lo que he señalado en el artículo "Contornos teóricos de la educación inclusiva", publicado en la Revista Boletín Redipe (2019), respecto de su estructura metodológica de naturaleza abierta. Trabaja conectando e incluso, explorando singulares formas de interrelación e interreferenciación a partir de cada una de las geografías epistémicas que confluyen y crean el conocimiento especializado del enfoque aquí analizado.

La estructura de producción que ensambla la propuesta 'inclusión como método' devela una compleja articulación de carácter multiaxial, en la que se cruzan, albergan y dislocan una amplia variedad de influencias, intereses, discursos, proyectos de conocimiento en resistencia, etc., cuyas formas de conexión, entrelazamiento, diálogo y movimiento operan mediante una acción extra-disciplinar, las que al ser rearticuladas y sometidas a complejas formas de traducción científica producen algo nuevo -objetivo claro en términos discursivos pero espinoso en su dimensión realística-, develando un entramado post-disciplinar. La arquitectura que construye la estrategia analítica significada como ‘inclusión como método' se moviliza por una amplitud enfoques críticos y post-críticos ${ }^{6}$, entre los cuales destacan, los estudios post-coloniales, post-estructurales, los estudios visuales, los estudios de la mujer, de género, queer, de feminismo crítico contemporáneo, de la filosofía política, de la diferencia, de la corriente interseccional, de la sociología de la discapacidad, de la sociología de la educación, de los estudios culturales anglosajones, asiáticos y latinoamericanos, preferentemente. Se convierte en un recurso analítico-metodológico dedicado a interrogar una variedad de proyectos de conocimiento, prácticas, estrategias y conceptos en resistencia. En efecto, construye una estrategia analítica que aleja su centro de configuración e interés de las lógicas formalistas implicadas en la construcción de repertorios metodológicos clásicos.

Al concebir 'inclusión como método' a través de las nociones de dispositivo de producción del conocimiento y sistema de recognición de las bases de la Ciencia Educativa, expresa un estatus de teoría de la actividad, espacio en el que conexionan y entran en contacto una amplia variedad de compromisos intelectuales y éticos, debates, intereses y preocupaciones analíticas que trabajan a favor del descentramiento de las consciencias explicativas de la actividad pedagógica. Su heurística devela un singular mecanismo de

${ }^{5}$ Trabajo que presenta la conferencia magistral impartida por invitación en el Programa de Doctorado en Ciencias de la Educación de la Universidad Nacional del Centro del Perú, Huancayo, Perú, en 2017.

${ }^{6}$ Cada uno de ellos -incluso, los no nombrados- corresponden a los campos de confluencias que crean y garantizan la producción de su conocimiento. 
recognición y transformación de las dinámicas políticas y analíticas que sostienen los marcos metodológicos desprendidos de cada uno de los campos de confluencia que crean y participan de la producción de su saber. En efecto, deslinda un corpus de proyectos de conocimiento, dedicados a formular otros tipos de ingenierías educativas. Inclusión como método se convierte en una estrategia analítica dedicada a interrogar las diversas geografías epistémicas que participan de su campo de producción. Construye una singular estrategia analítica que fomenta la experimentación del pensamiento educativo. Sus propósitos desbordan las preocupaciones referidas a la creación de un singular 'diseño de investigación' o una 'metateoría' que, a momentos, pueden convertirse en una camisa de fuerza, sino más bien, construye una compleja matriz de “investigación analítica, más que una alineación o prescripción específica para enfoques o técnicas metodológicas particulares" (BURMAN, 2017, p. 12).

Si aceptamos la afirmación que la educación inclusiva enfrenta un desafío definitorio crucial, esto es, participa de las relaciones de poder y de las representaciones culturales que interroga, entonces, elabora una crítica significativa a los fundamentos conceptuales, políticos, metodológicos y a los vocabularios disponibles empleados por las Ciencias de la Educación, que establecen alianzas imperceptibles con proyectos de conocimiento dedicados a reproducir la dominación, al tiempo que profundizan y enmascaran las desigualdades. Por esta razón, prefiero concebir dicha categoría en tanto proyecto de resistencia epistémica principal característica de su episteme-. Su carácter indisciplinar desarrolla nuevas formas interpretativas del sistema-mundo y de sus reglas de funcionamiento institucional, ofrece marcos para repensar el lugar de la inclusión en tanto espacio de producción del conocimiento y mecanismo que performa la realidad. Atiende al corpus de relaciones, intermediaciones e interreferenciaciones 'entre' -y-cidad-y 'más allá' -post-disciplinariedad- de los contextos y de las circunscripciones intelectuales que confluyen, crean y garantizan la producción de su saber.

La interrogante por el método, si bien, constituye una preocupación significativa en los estudios teóricos, así como, en la formación de los educadores e investigadores ${ }^{7}$ en el terreno de la educación inclusiva, reconoce el déficit epistemológico y metodológico que atraviesa su campo. La analítica que impone 'inclusión como método' fomenta un diálogo entre enfoques que, en ocasiones, alejados de la actividad científica que designa el objeto de la inclusión. La

${ }^{7} \mathrm{La}$ formación de los investigadores para la educación inclusiva constituye un campo de baja intensidad y exploración. Devela un punto espinoso. 
'inclusión' y la 'educación inclusiva'8 en tanto categorías de análisis constituyen poderosos tropos teórico-políticos. En efecto, comparto la preocupación e insistencia efectuada por Burman (2017), acerca de la relevancia de "destacar que este proceso de documentación va más allá de la descripción para poner bajo escrutinio crítico las prácticas ético-políticas involucradas en la elaboración, interpretación y aplicación y recepción de material de investigación” (p. 20). Inclusión como método estructura su actividad a partir del principio de audibilidad $^{9}$ (OCAMPO, 2019). La sección del sintagma referida a la inclusión al construir un dispositivo de intervención crítico-política en la heterogeneidad de micro-prácticas y microopresiones constitutivas del sistema-mundo a través de la matriz colonial del saber, del ser y del poder, configura una analítica intersticial que recoge las contribuciones de Chen (2010 y 2012), Coșobea (2017) y Burman (2017). Los dos autores mencionados primeramente, inscriben su actividad en los estudios culturales asiáticos, mientras que, Burman, inscribe su quehacer en la crítica deconstruccionista del desarrollo humano, cuya geopolítica la sitúa en el contexto de la psicología crítica anglosajona. El punto de convergencia entre cada uno de ellos, reside en la configuración de una economía política de la justicia y la inclusión para una geopolítica en permanente movimiento y dinamismo, cuyos contenidos críticos emergen del entrecruzamiento, el desbordamiento, de la rearticulación, la traducción y la excedencia disciplinaria.

Inclusión como método opera más allá del signo que puede describir su función en términos de un tropo epistémico, político y ético, su fuerza teórica lo describe en tanto

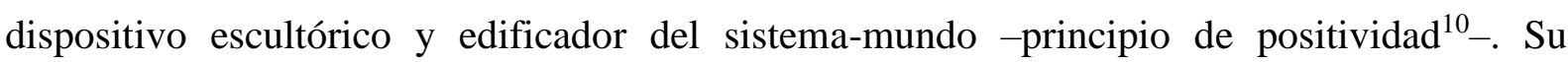
arquitectura analítica opera en el diaspórismo, en el movimiento rizomático y poliangular, así como, en la experiencia migratoria de una diversidad de singularidades intelectuales que, al encontrarse, dialogan y se reorganizan mutuamente -principal operación de la diáspora epistémica ${ }^{11}$ -. $\mathrm{Su}$ arquitectura reside en lo más profundo de la 'y-cidad' de la educación inclusiva. Sin duda, este punto merece una nota a pie de página. En efecto, el sintagma ‘inclusión como método', rescata el potencial político y heurístico que reside en su función,

\footnotetext{
${ }^{8}$ Nociones hipónimas.

${ }^{9}$ Propiedad que surge del encuentro y rearticulación de las categorías de 'performatividad', 'intransitividad' y 'escultórica'. La audibilidad se asocia con el ethos que instala a nivel de conciencia del espectador/interpretante. Devela una compleja operación cognitiva, que sólo con escuchar dicha categoría activa otros niveles de sensibilidad y conciencia social. Audibilidad y capacidad escultórica participan en la consolidación del enlace de realización.

${ }^{10}$ Principio epistemológico de la educación inclusiva, junto a los de heterogénesis, exterioridad, conexión dinámica y morfo-dinámica, multiplicidad, interseccionalidad y diaspórismo epistémico-metodologico y síntesis disyuntiva.

${ }^{11}$ Concepto introducido por el autor de este trabajo.
} 
interpela las formas de producción del conocimiento y los legados epistemológicos que participan en el ensamblaje de su estructura de conocimiento -falsificada, hibrida y auténtica, enfrenta además, la pregunta por la comprensión sobre la autenticidad de su conocimiento, analiza las complejas formas de encuentro, movimiento, relación, rearticulación y traducción de cada una de sus singularidades y recursos epistémicos, atiende a sus mecanismos de superposición entre diversos proyectos intelectuales, forja un proyecto de naturaleza postdisciplinar. Fomenta un nuevo estilo de relacionamiento, rompe con la fuerza esencializadora y opresiva de las interpretaciones binaristas, proponiendo una analítica más amplia para entender los procesos de relegamientos y resistencias que tienen lugar al interior de determinadas estructuras de escolarización y participación social, cultural, políticas y económicas. Favorece la descolonización de las matrices interpretativas que participan en la formación del conocimiento de la educación inclusiva.

Al examinar el valor heurístico de la cadena de palabras 'inclusión como método', observo necesario analizar el lugar que desempeña la inclusión en él. Puede entenderse como un espacio de experimentación y fractura del pensamiento educativo, un compromiso de imaginación, una política de transformación del mundo, una singular forma de imaginación epistémico-política, o bien, un dispositivo de reingeniería del quehacer educativo. Todas estas denominaciones se encuentran imbricadas en los principios de positividad -edificación-, audibilidad y escultórico de la educación inclusiva. Su terreno epistemológico trabaja a partir de un conjunto de relaciones exteriores y en una estructura de síntesis disyuntiva, espacio en la que entran en contacto, mediante la performatividad de lo re-articulatorio, una amplia variedad de recursos epistémicos, cuya acción "invierte las relaciones entre las ideas 'dominantes' y las experiencias de los grupos 'marginados', al colocar a estos últimos en el centro como la fuente de una multiplicidad de nuevos flujos” (GAZTAMBIDEFERNÁNDEZ; THIESSEN, 2012, p. 8).

Si bien, las zonas más importantes del pensamiento de la educación inclusiva emergen por vía de la contribución de la post-crítica, la naturaleza de su saber auténtico va más allá de estas designaciones. El redescubrimiento de su valor heurístico posibilita marcos de entendimientos más complejos, develando una orientación afectiva y la creación de un singular estilo y formato de subjetividad. La inclusión desafía los deseos y tecnologías residuales que proliferan de la matriz de poder, saber y ser, concebidas en términos de patologías sociales crónicas y formatos del poder. Finalmente, quisiera destacar que, la inclusión -fenómeno y campo- y la educación inclusiva -circunscripción intelectualconstituyen un movimiento analítico, cuya epistemología se convierte en una estrategia de 
dislocamiento y transformación de las estructuras, prácticas y agencias implicada en la producción de su conocimiento y sus formas de reduccionismo y educacionismo metodológico. Esto es lo que la hace ver en tanto estrategia analítica conflictiva. La inclusión ratifica un compromiso mutuo con una amplia variedad de enfoques post-críticos, lo que exige un análisis basado en mecanismos de interreferenciación, es decir, explora la multiplicidad de puntos de encuentro que operan bajo la condición del pensamiento relacional y de formas específicas de constelación intelectual. Inclusión como método devela una empresa que se encuentra incorporada en distintos proyectos de conocimiento, sin poseer necesariamente esta denominación. ¿De qué modo trabaja el significante de la inclusión?, esencialmente, asume que "los problemas epistemológicos clave y los desafíos políticos se plantean por cómo viajan las ideas y cómo se abordan en diversos contextos" (GAZTAMBIDE-FERNÁNDEZ; THIESSEN, 2012, p. 9). A través de esta afirmación es posible destacar la naturaleza diaspórica de la educación inclusiva caracterizada por intensos flujos, movimientos y formas de constelación, compuesta de múltiples orígenes y complejas y contradictorias corrientes y memorias que crean y garantizan la producción de su saber.

El adjetivo 'inclusiva' en el sintagma 'inclusión como método' opera en tanto estrategia analítica y concepto crítico de las referencias que participan de la producción de su saber. Inclusión como método sirve para interrogar los modelos de desarrollo de la educación, la justicia, la diferencia, la singularidad, etc., la inclusión como método se concibe como una intervención analítica relacionada, ayuda a explicar cómo este fenómeno se encuentra vinculado a través de un conjunto de anudamientos o enredos genealógicos implicados en la construcción de su conocimiento. Inclusión es algo más que un simple objeto de investigación, un campo semántico y un terreno analítico integrado por una amplia variedad de enfoques objetos de traducción y rearticulación permanente. Emerge así, un dispositivo epistemológico de fractura, alteratividad y transformación del pensamiento educativo, cuyas implicancias se proponen "suspender, para evocar una categoría fenomenológica, el conjunto de prácticas disciplinarias que presentan a los objetos de conocimiento como previamente constituidos e investigar, en cambio, los procesos a través de los cuales estos objetos son constituidos" (MEZZADRA; NEILSON, 2012, p. 36-37).

La sección del sintagma referida al 'método', toma distancia del corpus de concepciones canónicas que conciben lo metodológico en términos de un conjunto de determinadas técnicas neutrales aplicadas a un objeto. Inclusión como método, se propone configurar una analítica capaz de alterar los modos a través de los cuales su objeto falsificado e hibridizado, incluso, auténtico- ha sido construido, sigue la lógica de la 
performatividad del método propuesta por Law (2004). La inclusión supera el corpus de concepciones canónicas, ya que en sí misma, es un método-, instaura una singular forma de producción del conocimiento, cuyo objetivo consiste en atender al corpus de "relaciones de dominación, desposesión y explotación están siendo redefinidas en el presente sino también de las luchas que adquieren forma en torno a estas relaciones cambiante" mediante proyectos de conocimiento que avalan dichos propósitos" (MEZZADRA; NEILSON, 2012, p. 37). Inclusión como método designa una singular estrategia de análisis aplicada a la construcción del conocimiento especializado de la educación inclusiva, entonces, forja un campo de multiposicionalidades de proyectos intelectuales y políticos de resistencia. Ofrece un marco superador de la figuración reduccionista y neutral, significado en términos de un adjetivo prototípico y abstracto -ideas que permiten develar su ambigüedad teórica y política, cargado de usos universalizadores y ahistóricos y sus implicancias despolitizadas- con presencia en diversos proyectos intelectuales y movimientos sociales contemporáneos, específicamente, ligados al antirracismo, la justicia social, la equidad, etc.

La sección del sintagma referida al 'método' describe un sistema de imaginación desafiante acerca de una amplia multiplicidad de problemáticas estructurales. A su vez, es un compromiso crítico y un conjunto de proyectos políticos y de conocimiento en resistencia, lo que según Burman (2017, p. 25) sugiere "estar abierto a, incluso abrazar, la influencia de otros marginados, rechazar concepciones estrictas de los orígenes y permitir que evolucionen los métodos 'basados en otras geografías'” (GAZTAMBIDE-FERNÁNDEZ; THIESSEN, 2012, p. 10). Inclusión como método se propone dislocar las formas analíticas clásicas para aproximarse a la comprensión de la educación inclusiva, devela un compromiso deconstruccionista, tropológico y descolonizador, su fuerza analítica redescubre la potencia de lo 'des-' y de lo 'post-', descubre distintas condiciones de conocimiento, sigue una metodología de interreferenciación.

La inclusión al crear un nuevo estilo de singularidad reconstruye el yo. Inclusión como método puede leerse en términos de un dispositivo de transformación de sus debates analíticos-metodológicos, su singularidad incide en la forma de producción del conocimiento y en la forma que debiesen adoptar los estudios sobre educación inclusiva, recupera su agencia epistemológica rearticulando una amplia variedad de conceptos, objetos y disciplinas, que dialogan de mejor forma con su entorno. Cristaliza un punto de referencia entre muchas contribuciones, introduce la necesidad de responder al déficit epistemológico que atraviesa al campo de educación inclusiva, el que puede ser descrito en términos de una tecnología, es decir, un saber acumulado en prácticas. Asume un 'más allá' analítico -no lineal, ni 
secuencial-, se propone superar aquellas definiciones universalistas sustentadas en una relación dialógica y performativa entre diversos marcos conceptuales, en tanto enfoque analítico, se propone hacer referencia en términos de lo que la teoría afirma y lo que la práctica permite en los círculos intelectuales. Este análisis podrá ser complementado a través de la teoría del actor-red.

Inclusión como método articula un conjunto de conexiones configurando un marco novedoso para abordar sus formas analíticas, designa en tal caso, un proyecto en curso, configura una red o malla de conexión estriada que alberga una amplia heterogeneidad de prácticas teóricas y metodológicas alrededor del significante establecido como 'educación inclusiva'. Su singularidad devela una complejidad analítica que puede convertir su entramado en un proyecto ideológico. Al considerar un enfoque analítico, inclusión como método, articula una fuerza teórica que da cuenta de un singular movimiento reflexivo, da paso a una concepción de un nuevo acto y motivo político. La inclusión es una forma de replicar lo político. Uno de los intereses centrales que residen en la perspectiva 'inclusión como método', consiste en cambiar -más bien, alterar y visibilizar- a través de un patrón recognoscitivo, las condiciones de producción del conocimiento educativo. Se convierte en una estrategia analítica, en la que la sección del sintagma 'inclusión' se emplea en términos de un punto de anclaje y referencia epistémica en la comprensión de una amplia variedad de problemas educativos de carácter complejos, razón por la cual, prefiero concebir en términos de un pegamento epistémico o un concepto maleta.

La diversidad de hebras teóricas que participan de su campo de producción proporciona horizontes y perspectivas alternativas con el objeto de configurar una comprensión diferente del mundo. Inclusión como método es algo que se explica por sí mismo, multiplica los puntos de conexión entre diversos marcos intelectuales, inclusión es un concepto político, una categoría histórica, una noción analítica, un espacio de producción configurado a partir de constantes enlaces, traducciones y rearticulaciones que aperturan posibilidades heterológicas de análisis. Es un entramado conceptual que se nutre diversos autores, perspectivas, formas de análisis y teorías, es un problema gramatical complejo. Crea sus valores propios, se propone crear un conocimiento específico acerca de la regionalización denominada en tanto 'inclusión' y 'educación inclusiva', contribuyendo a superar la monopolización de carácter falsificada que emerge por vía de los planteamientos de la educación especial, multiplica los puntos de referencia, crea un terreno fértil y común para la producción del conocimiento. Estas formas de producción -que en el terreno de la educación inclusiva han operado de forma imperceptible, constituyendo tópicos de análisis e 
investigación especializados por parte de sus investigadores- traza diversas políticas de representación de sus sujetos -incidiendo y modelizando en su política ontológica ${ }^{12}$ -

El trabajo que propongo observa cómo la inclusión ha sido inscrita en términos de una imaginación falsificada de lo especial -insistencia y provincialización justificada en un corpus de fracasos cognitivos-, un singular territorio en el que se mezclan las luchas por la justicia, la equidad, la igualdad y el racismo, sin orientarse hacia la constitución de una poderosa herramienta de transformación del mundo. Inclusión como método construye una estrategia específica para abordar una complejidad de problemas educativos, proponiéndose multiplicar los marcos de referencia. Cristaliza una singular matriz de intervención e imaginación político-epistémica.

\section{Inclusión: una teoría viajera, post-disciplinar y re-articuladora de lo 'post-crítico'}

El campo de educación inclusiva es un terreno fundamentalmente disputado por una multiplicidad de disciplinas, teorías, objetos, métodos, territorios, sujetos, influencias, modos de análisis, conceptos, saberes, compromisos éticos y proyectos políticos. Construye un espacio no-disciplinar; no fijo en ninguna disciplina y en ninguno de los aportes antes indicados. Más bien, viaja permanente y no-linealmente, por cada uno de ellos, en cada nuevo aterrizaje extrae lo más relevante y significativo de cada recurso epistemológico, con el propósito de fabricar un nuevo objeto y saber. Su comprensión rebasa los límites disciplinarios al reconocer que las formas de conocimiento que le son propias se resisten a operar en una lógica exclusionaria, repercutiendo seriamente en la organización de los procesos de formación del profesorado, producto de la fragmentación de sus disciplinas ${ }^{13}$. La configuración teórica de la educación inclusiva opera en el movimiento, en el encuentro, en el pensamiento de la relación, en el caos y en la constelación; forja una estructura de conocimiento abierta, compuesta por un conjunto de prácticas teóricas y metodológicas heterogéneas, cuya funcionalidad reside en el concepto de síntesis disyuntiva.

¿Es la educación inclusiva una disciplina? Como aproximación preliminar, afirmaré que no, puesto que, su objeto no puede ser delimitado en los paradigmas actuales de ninguna disciplina. No pertenece a la región de educación especial, si se ha establecido su relación, es básicamente por la incapacidad del campo y de sus investigadores para comprender sus objetos. La incomprensión de su objeto es influenciado por el significado establecido por la

\footnotetext{
${ }^{12}$ Política ontológica de lo menor, fundamentalmente, articulada en la concepción de múltiples singularidades.

${ }^{13}$ Instala una formación paradisciplinar. Para mayores detalles, véase: "La enseñanza de la Educación Inclusiva y la pregunta por el método: un análisis antidisciplinar".
} 
educación especial, convirtiéndose en un significante erróneo o bien, que instrumentaliza e inscribe su actividad. Continuar concibiendo la educación inclusiva como educación especial, sería condenada a repetir el mismo fallo. A pesar de no presentar estatus disciplinario, fabrica un objeto ambivalente, complejo y multidimensional, de carácter, eminentemente, fronterizo y post-disciplinar, articulando cuestiones específicas en torno a este objeto, vinculadas esencialmente a la educación, pudiendo ser aplicado en términos sociales, políticos, culturales, etc. Concebida así, configura un objeto abierto, utilizándose de diferentes maneras. La falta de claridad sobre la naturaleza de su dominio continúa siendo uno de los puntos más críticos de su teoría. Una interrogación con estas características instituye una reflexión programática sobre el sentido y alcance de su trama epistemológica. ¿Por qué la Educación Inclusiva concierne a la educación en general?

La afirmación: 'la educación inclusiva es una teoría sin disciplina', no sólo refiere al conjunto de elementos que participan de su circunscripción intelectual y de sus ámbitos de formalización académica, sino que iluminan su función y la apertura de su estructura disciplinaria a partir de contribuciones provenientes de lo anticolonial, lo post-colonial, la corriente interseccional, el feminismo, la filosofía política, de la diferencia, los estudios visuales, la teoría crítica, los estudios queer, de género, de la mujer, la interculturalidad crítica, la física, los estudios de la subalternidad, el pragmatismo, etc., convirtiéndose en una categoría analítica de intermediación. Si ésta no se encuentra fija en ninguna disciplina, ¿de qué manera es posible circunscribir el dominio de su objeto? Tradicionalmente, los dominios disciplinares son definidos a partir de sus objetos de estudios, pero, ¿qué sucede cuando éste rebasa los límites disciplinarios históricamente aceptados y legitimados?, construye su saber por fuera de cada uno de sus aportes que son capturados en una malla de conexión, posibilita la resolución de problemas ante una variedad de temáticas -heterotopicalidad-, instala una nueva manera de pensar y asumir los problemas educativos. La educación inclusiva como práctica crítica otorga respuestas complejas. Al respecto, Bal (2004) indica que

[...] el estatus de tal movimiento dentro del pensamiento y la organización académica. La respuesta a si nos estamos enfrentando con una disciplina o con una interdisciplina dependerá de cuál sea su objeto. Si el dominio de su objeto consiste en el conjunto de materiales consensuadamente categorizados, alrededor de los cuales han cristalizado ciertas hipótesis o aproximaciones, estaríamos tratando con una disciplina (p. 12-13).

La configuración de la estructura intelectual relacional de la educación inclusiva, no surge por vía de acumulación de disciplinas o disposición de un conjunto de éstas organizadas en torno a un tema, más bien, dicha opción deviene en una empresa estéril en la construcción 
de un campo y objeto de conocimiento. Su dimensión post-disciplinar consiste en crear un objeto que no le pertenece a nadie. Sobre este particular, insiste Bal (2004) agregando que, "la idea de crear un objeto nuevo que no pertenezca a nadie hace imposible definir su dominio como una agrupación de elementos" (p. 13). Emerge por vía de desarticulación y rearticulación de cada uno de sus elementos, en la discontinuidad y en el vuelco, forja una estructura de conocimiento que sigue la lógica hegeliana de totalidad dinámica, cuyas posiciones y elementos de confluencia -objetos, métodos, teorías, influencias, sujetos, territorios, marcos teóricos y políticos mediante los cuales se moviliza la categoría de inclusión- se entrelazan y engendran unos con otros. Al afirmar que, epistemológicamente, la Educación Inclusiva emerge de un conjunto de enredos genealógicos de dispersión, refiero a una estructura dinámica de entrelazamiento discontinuo, la cual, consagra una práctica analítica y metodológica abierta.

Al constituir un campo de complejas, dinámicas, heterogéneas e intensas influencias, interesa mapear el tipo de continuidades, rupturas y vuelcos que en ella tienen lugar. El campo epistemológico de la educación inclusiva es un terreno de múltiples temporalidades teóricas y metodológicas, dimensiones que determinan su profundidad y duración. Interesa demostrar el tipo de relaciones que son establecidas entre cada una de ellas. ¿Qué tipo de determinación intelectual, ética, política y pedagógica forja la noción inclusiva? Su campo es un espacio de profundas continuidades históricas y trans-epistémicas, integrado por coyunturas más breves. Pensar el estilo de coyuntura que forja la educación inclusiva posee un conjunto de especificidades particulares que exigen determinar lo que cambia, lo que permanece, sus modalidades de dislocación, desarticulación y rearticulación. Como estructura y campo de conocimiento no posee una inclinación por una disciplina particular -sobre aquello que es históricamente específico-, se interesa por las diferencias que emergen de sus sistemas de continuidad. Coincidiendo con Hall (2011, p. 50) si cambia la coyuntura, será necesario repensarlo todo. Cada una de sus disciplinas y aportes se movilizan dentro y fuera de sus marcos de referencia. Es un lugar indisciplinado por naturaleza. 


\section{Inclusión como género}

La educación inclusiva como género ${ }^{14}$-naturaleza- es eminentemente heterogénea, sus obras y ejes temáticos se encuentran vinculados a una multiplicidad de dominios y territorios de análisis - construye una epistemología posicionada en permanente movimiento-. Este complejo mapa plurilocalizado se moviliza a través de un corpus de estudios críticos, como teoría educativa transformadora, interviene en un debate vivo y confuso que trae a colocación las formas de violencia e injusticia relacional y estructural endémicas en la constitución del mundo. En sí misma, es una teoría recognoscitiva. Sus contornos teóricos no fijos, ni delimitables en los marcos de ninguna disciplina, hacen difícil responder a la interrogante que aborda el tipo de género a la que ésta pertenece. Epistemológicamente, es un género que opera mediante la metáfora deleuziana de 'malla de conexión', un discurso entrelazado en distintos puntos a objetos, métodos, disciplinas, interdisciplinas, conceptos, teorías, etc. - de allí que, se afirmé que, este, es un territorio que surge de complejos enredos genealógicos-. La teoría de la educación inclusiva concebida simplemente como ampliación y diversificación de la teoría educativa contemporánea, puede ser interpretada en términos de un campo dinámico, de una fuerza que empuja y altera el pensamiento hacia el futuro, se desplaza hacia movimientos inesperados. Concebida así, se expresa en términos de un espacio de mutación y multiplicación intelectual, ética y semántica. Sus ámbitos de análisis son significados a través de la categoría de pre-emergentes (WILLIAMS, 2003), cuya fuerza analítica le otorga sustancia a los demás. Los conceptos epistemológicos de la educación inclusiva constituyen poderosas herramientas políticas de intervención y transformación del mundo.

La pregunta por el género devela una singular constelación de textos, que instalan "nuevos significados y valores, nuevas prácticas, nuevas relaciones y tipos de relaciones que se crean continuamente” (WILLIAMS, 2003, p. 104). Las discusiones contenidas en cada uno de ellos, encajan perfectamente con la heterotopicalidad de análisis que circulan, se entrecruzan y rearticulan en su interioridad. Si bien, establecen condiciones de afinidad, éstas, no siempre son armónicas, en ocasiones afectadas por múltiples condiciones de contaminación -dominios que no pueden ser separados-, diálogos, interpelaciones, movimientos, giros y rearticulaciones permanentes. Su fuerza analítica se impone por medio

${ }^{14}$ Forma una compleja mezcla de géneros cuya autenticidad se logra por vía de la traducción y de la rearticulación. La naturaleza epistemología de la educación inclusiva se caracteriza por ser un campo de desbordamientos insospechables, rearticulaciones permanentes y cruces de géneros que operan más allá de las estructuras académicas convencionales. 
de la deconstrucción de la visión neo-especial -constituye en lo pedagógico su principal conflicto teórico- que entroniza y erige la formación del profesorado. A su vez, vector bivalente significado como un centro hegemónico de articulación -tiranía intelectual en la formación y la investigación- y un error persistente en la construcción de su conocimiento especializado. Interesa documentar en qué momento se convierte en la explicación de mayor acceso a la comprensión teórica -que no es otra cosa que, pseudo-teórica- a la que recurren creadores de políticas públicas, investigadores, académicos y profesionales de la educación para justificar sus elecciones. Pensar la configuración del campo de educación inclusiva en términos de género, coloca en contexto conceptos, ideas y saberes que desbordan la convencionalidad de sus tecnologías de análisis. Como campo de fuerzas, la inclusión, crea una vigilancia crítica que opera en la exterioridad epistemológica, es decir, en el afuera. Se niega a la opción de cerrar sus posibilidades analíticas a lo dicho. Su acción acontece en el redoblamiento y en la infinitud.

¿Qué implica exactamente entrelazar una heterogeneidad de textos en el estudio de la educación inclusiva? Lo primero, es que los sistemas de entrelazamiento permiten rearticular diversas clases de géneros con el objeto de elaborar respuestas innovadoras ante la multiplicidad de problemas educativos. Ofrece un conjunto de posibilidades analíticas para indisciplinar el campo de producción, es decir, abrir sus condiciones de elaboración a mediaciones epistemológicas y metodológicas más complejas. Fundamentalmente, a través del giro, la rearticulación y la traducción de sus elementos alcanzan la cristalización de un nuevo objeto y saber. El 'entrelazamiento' en tanto categoría de análisis, apoya la edificación de un nuevo marco teórico. A la fecha, el marco teórico articulado en la interioridad del centro hegemónico del campo, puede ser significado a través de la metáfora deleuziana de novedosidades, es decir, contenidos, lenguajes, principios y fundamentos que parecen innovadores, al tiempo que, su potencia analítica conduce a trabajar sobre más de lo mismo.

La configuración de un método crítico sobre educación inclusiva tendrá como misión responder al conjunto de fuerzas que convergen en su momento fundacional en tanto circunscripción intelectual y espacio de formalización académica -estudios sobre educación inclusiva-. Si bien es cierto, éste género comparte una amplia variedad de conceptos y categorías de análisis con algunos de sus dominios genealógicos más relevantes, lo cierto es que, sus significados y fuerza conceptualizadora se alteran y transforman en cada nuevo arribo. Este territorio puede ser significado como un epicentro crítico del pensamiento educativo contemporáneo. Cada uno de los elementos confluyentes en su estructura teórica interactúa en un sistema complejo. Volviendo a la pregunta por el tipo de género que 
construye la educación inclusiva, observo necesario discutir en torno a las condiciones de relación entre sus géneros y sub-géneros confluyentes. En otras palabras, cómo las estructuras cognoscentes se rearticulan en la formación de un nuevo objeto. Cada grabado, huella, memoria o enredo genealógico identificado como parte de la diversidad de géneros que participan de la configuración de su territorio, asumen la metáfora de 'lo residual' que, a juicio de WILLIAMS (2003) asume la forma de algo que ha sido formado/constituido en el pasado hallándose aún en actividad en el presente. Muchos de ellos, asumen un estatus de signos interrogadores del presente. Producto de este tipo de expresiones, prefiero concebir parte del legado epistemológico de la educación inclusiva en tanto circunscripción intelectual a través de la categoría de 'palimpsesto'. En efecto,

[...] debemos hallar otros términos para la innegable experiencia del presente: no sólo para el presente temporal, la realización de esto y de este instante, sino la especificidad del presente, lo inalienablemente físico, dentro de lo cual podemos discernir y reconocer efectivamente las instituciones, las formaciones y las posiciones, aunque no cierre como productos fijos, como productos definidores (WILLIAMS, 2003, p. 150).

Las obras que apoyan la empresa indisciplinadora del campo, explicitan una operación extradisciplinar, es decir, sus ejes de constitución analíticos no proceden desde la interioridad de la literatura científica y de las investigaciones elaboradas por parte de la Ciencia Educativa. Más bien, se conectan en algún punto de análisis a la comprensión de su dominio y objeto. Su centro crítico de producción recurre a la metáfora del cruce de límites y desbordamiento de los márgenes disciplinarios, metodológicos y discursivos de una amplia multiplicidad de géneros. Las obras y escritos que permiten pensar la formulación de una nueva teoría educativa crítica se encuentran entrelazadas a otros contenidos y escritos configurando un dominio del tipo palimpsesto, espacio en el que las huellas del pasado develan un hilo de continuidad, cuya vigencia y aplicación se obtiene por complejos mecanismos de rearticulación. En estricto sentido, su campo de tematización no es ni filosofía, ni antropología, ni postcolonialidad, ni feminismo, ni sociología, ni psicología, ni exclusivamente, la educación convencional, etc. -recurre a todas ellas, extrae lo más significativo sometiéndolas a complejas tecnologías de traducción-, es un terreno de interpelación y disputa, que construye una especificidad diferencial en el abordaje de los fenómenos educativos. Diversas obras que permiten pensar otras posibilidades de análisis aplicadas a la configuración del espacio escolar, político, social y cultural, así como, la comprensión estética sobre el sujeto -política ontológica de 'lo menor'-, etc., no son significadas como parte medular de la teoría de la educación inclusiva. Emerge aquí, un 
problema de horizonte de expectativas, desempeñando un papel medular en las modalidades de construcción de significados de sus textos. Pensando en las condiciones formativas que deben cautelarse en la educación de los futuros profesores, será necesario examinar qué es lo que realmente leen los textos concebidos en términos de obras clave o literatura obligatoria sobre educación inclusiva. Un examen aplicado devela una imperceptible política epistémica que modela los rumbos de los programas y procesos formativos del educador. Es, ante todo, un ejercicio crítico.

La construcción teórica de la educación inclusiva es más que una simple rearticulación de discursos; rechaza toda forma de dependencia intelectual, no se resigna a la articulación pasiva y pseudo-armónica entre elementos heterogéneos que conviven en su interioridad. La mezcolanza es un signo de arbitrariedad devenido en una política de todo vale, que conduce a la proliferación de diversos errores en la producción de su conocimiento, mediante la aplicación de complejas formas de traducción. Esto es lo que permite salir de la lógica del aplicacionismo epistémico y apostar por la performatividad de lo rearticulatorio con la intención de producir un nuevo objeto y saber. Una de sus tareas críticas asume el reto de develar el género implícito que articula el giro epistemológico y metodológico - de carácter post-disciplinar- de la educación inclusiva, herramienta clave para la determinación de las luchas que enfrentan la multiplicidad de colectivos más allá de los sistemas de enmarcamientos de la razón esencialista y construccionista. ¿Qué tipo de análisis nos ofrecen los textos actualmente significados como literatura obligatoria en los programas de formación del profesorado sobre educación inclusiva? Como puntapié inicial, sostendré que, son textos, en su mayoría, producidos en la interioridad de una estructura de conocimiento 'falsificada' y de un significante mainstream neo-especial -objeto perdido, incapaz de colocarlo dentro de un marco multicausal de problemáticas-.

Finalmente, qué enseña la formación y cómo enseña a leer el mundo. Aquello que asignamos leer a los estudiantes desempeña un papel fundamental en la educación de la mirada, en el fortalecimiento de su conciencia y pensamiento. Se convierte en una estrategia de trazabilidad para intervenir el mundo y operar en él. La configuración del género denominado educación inclusiva conduce a la proliferación de una 'consciencia práctica', impone una temporalidad que desborda y trastorna el tiempo pedagógico históricamente legitimado, cuyos significantes contrarios y erróneamente instalados, resguardan la funcionalidad del cronosistema, es decir, un tiempo y un espacio único, en el que la totalidad de estudiantes concebidos como multiplicidad de diferencias, hacen lo mismo, en un mismo tiempo y espacio; acción contraria a toda expresión de singularidad o revolución molecular. 
La noción del tiempo en tanto categoría filosófica es clave en la comprensión epistemológica de la educación inclusiva. Sin embargo, no constituye un tópico de análisis abordado por los investigadores. La noción de tiempo coherente con la multiplicidad de diferencias presentes en el espacio escolar es la 'heterocronía de aprendizaje', es decir, la presencia de diversos tiempos en la intimidad del aula. A través de esta visión, se concibe la praxis educativa, social y cultural atravesada por múltiples tiempos, sujetos multi-temporalizados en sus agencias y expresiones cognitivas. La presencia de múltiples tiempos es coherente con la heterogeneidad del espacio.

El objeto de trabajo de la educación inclusiva impone 'otro lugar', es decir, al constituir un fenómeno de carácter post-disciplinar, forma un género singular en su constitución. Recurriendo al uso de las categorías identificadas por Genete (1989) en "Palimpsestos: la literatura en segundo grado", el género intelectual de la educación inclusiva bordea la especificidad de la transtextualidad y la transcientificidad rearticuladora.

La educación inclusiva al constituir un objeto fronterizo, membránico y postdisciplinar, devela un estatus de complejidad, precedida por la naturaleza del propio fenómeno, mientras que, la singularidad de su construcción, impone la fuerza categorial de 'architexto', es decir, el conjunto de categorías trascendentales que mediante la lógica del residuo dan vida a un campo singular. Su objeto y campo, pueden describirse a través de la categoría de trans-textualidad rearticuladora, visualizando formas en las que el fenómeno es puesto en relación con otros tópicos, fenómenos y campos de análisis, etc., demostrando singulares formas de re-entrelazamiento. Si bien, su campo de conocimiento se caracteriza por una articulación de complejas influencias, ninguna de éstas funciona en términos armónicos, ni de co-presencialiadad. Lo entrópico y lo diaspórico del territorio, permite reconocer la confluencia de elementos de diversos géneros que participan de la fabricación de un nuevo saber, lo que no quiere decir que algunas ideas y conceptos se encuentren necesariamente incluidos en otros. Si bien, una de las estrategias de construcción del conocimiento de la educación inclusiva opera a través del injerto, no siempre alcanza la creación de algo nuevo. Su campo a través de la metáfora de lo 'neo-especial' puede ser descrito en términos de un pastiche, mediante la combinación de diversos elementos, parece dar paso a la emergencia de algo completamente nuevo que no es tal.

La architextualidad de su dominio se expresa mediante la condición extra-disciplinar involucrada en su constitución. A través de ella, se vinculan diversas singularidades epistemológicas, campos de conocimientos, conceptos, etc., a pesar de que cada una de ellas sea sometidas a complejas formas de rearticulación, traducción y examinación topológicas, 
algunos de sus aspectos más significativos continuarán operando en términos residuales y palimpsésticos. El objeto de la educación inclusiva evoca a través de determinados ejes de análisis, ideas, luchas, memorias y legados, que no necesariamente son convocados literalmente. Producto de este fenómeno, múltiples campos y legados que contribuyen significativamente a transformar sus sistemas de razonamientos, los que han sido omitidos, arrestados y cooptados de la formación de los educadores. El campo de producción de la educación inclusiva puede ser significado en términos de un terreno meta-epistemológico, lo que designa la necesidad de mapear sus metatextos.

La enseñanza de la educación inclusiva no constituye un centro de análisis contingente por parte de los investigadores educativos y de las instituciones formadoras de educadores a nivel de pre y post-graduación. Un aspecto clave en la consolidación de una consciencia crítica sobre el sistema-mundo, requiere de la formación de un lector crítico de la realidad y de sus fenómenos, así como, de procesos formativos que fortalezcan la construcción de sus significados asociados. Ambos, constituyen poderosos procesos formativos de carácter hermenéuticos. La configuración de un 'método crítico' aplicado a la comprensión epistemológica de la educación inclusiva, construye su actividad heurística a través de la determinación de aquello que leen sus obras y literatura, así como, sus tecnologías de enmarcamiento, exigiendo atender a las condiciones de focalización que participan de sus principales interpretaciones. Al constituir el movimiento ${ }^{15}$ por la educación inclusiva un dispositivo reciente en la historia del pensamiento educativo, no se evidencian trabajos que con anterioridad, aborden la pregunta por las tradiciones interpretativas de sus fenómenos. Tampoco se identifican con claridad y legitimidad académica propia, un conjunto de reglas de interpretación que sus usuarios pueden aplicar en la lectura del mundo. Entonces, ¿cómo se enseña a leer el sistema-mundo en esta singular modalidad de encuadramiento teóricopolítico? Observo necesario examinar las formas de construcción interpretativas dispuestas en la interioridad de las estructuras académicas y el tipo de modalidades didácticas que apoyan dicha empresa.

\footnotetext{
${ }^{15}$ Prefiero el término 'movimiento' en vez de paradigma o enfoque debido al déficit epistémico-metodológico que ésta expresa y a la debilidad de sus sistemas de razonamientos para develar su estatus. En la actualidad el estatus de la educación inclusiva no está claro. Diversas voces afirman que se trata de un paradigma, un enfoque o perspectiva, lo cierto es que, su heurística desborda los problemas de un dominio o sub-dominio en particular, se interesa por abordar problemas educativos generales-estructurales de carácter complejo. La pregunta por el estatus a juicio de Ocampo (2019) explora, ¿qué es exactamente la educación inclusiva?, ¿es un concepto, un paradigma, una metáfora, un dispositivo heurístico, una metodología o bien, una teoría? Enmarcar la educación inclusiva a través de la noción de 'teoría' sugiere determinar cautelosamente que tipo de teoría designa. Sin duda, la educación inclusiva es un sistema de rearticulación de lo post-crítico.
} 


\section{Conclusiones: lo 'conjuntivo' del sintagma 'educación inclusiva'}

En esta sección me interesa analizar lo intermedio ${ }^{16}$ que reside en los términos 'educación' e 'inclusiva', es decir, las fuerzas analíticas e intelectuales que organizan el funcionamiento del sintagma. Inicialmente, articularé un análisis entre las dos partes del sintagma, examinando su potencial crítico y político. Examinaré en detalle la acción copulativa que existe entre ambos términos. También abordaré el potencial heurístico de dicha espacialidad y de las nociones ' $y$ - $e$ '. Es clave para entender qué estilo y naturaleza de fuerzas se ponen en juego en esta conjunción. ¿Qué características posee dicha conexión?, ¿es una conexión sin-sentido? El plano analítico aquí no se da por una condición coordinada, ni tampoco exclusivamente por una relación de subordinación. ¿Qué tiene la inclusión para enseñarnos sobre educación? No interesa asignar una posición de dominio a ninguna de las secciones comprometidas. Interesa ahondar cómo el mismo lugar donde significa y es significada la acción, reside una fuerza transformadora.

¿Cuál de ambas secciones del sintagma realiza la relación de transferencia y representación de la función de la educación inclusiva? En este caso, el lugar donde el conocimiento se significa es en la educación, mientras que, el lugar dónde es significada es la inclusión reside en la transformación del sistema-mundo. La inclusión hace la relación de interpretación, mientras que, la relación de transferencia queda sujeta a la educación. Fundamentalmente, el signo de inclusión ratifica una empresa deconstructiva que interpela y afecta a la noción de 'estructura' social, educativa, cultural, política, económica, etc. ¿Cómo se establecen los sistemas de implicaciones entre ambas? Se propone explorar aspectos que han sido soterrados en la comprensión de este signo. ¿Quién interpela a quién? y ¿quién es afectado por quién? La noción de implicación sugiere una relación de interioridad. El intersticio que articulan ambas nociones es regulado por un corpus de mecanismos de interimplicación, da paso a un campo membránico, en el que, a pesar de que ambas nociones presentan ideas similares, su especificidad diferencial es envuelta en un misma espiral de análisis. En ella, son comprometidas las interioridades de ambas piezas, forjan una relación de mutualidad, un sistema de interioridad recíproca, "puesto que cada una está contenida en la otra como su alteridad” (FELMAN, 1977, p. 6).

${ }^{16}$ Establece una condición más compleja y provocativa que una simple intersección. Me interesa explorar y develar el conjunto de elementos analíticos-metodológicos entrelazan y configuran el funcionamiento del sintagma. Esta dimensión es clave en la comprensión del objeto. Hasta aquí, la actividad significa de la inclusión expresa un carácter deíctico, es decir, una forma que está por llegar, orientada al futuro. Es, eminentemente edificador. 
La inclusión se convierte en un comentario performativo, cuyo efecto de doble intensidad reafirma su carácter dislocativo, alterativo y fracturante de la realidad y del pensamiento pedagógico. Su acción performativa devela un carácter provocativo. Al enunciarse la naturaleza del concepto despliega al menos tres poderosas acciones interpretativas. La primera, referida a su condición escultórica, proyectiva y arquitectónica. La segunda, explicita su condición de audibilidad y memoria social. Finalmente, la tercera, asume que, simplemente, "lo que el concepto hace al enunciarse es provocar cambios epistémicos y políticos” (FERNÁNDEZ, 2012, p. 11). Mientras que, Bal (2018) sostiene que, el sentido "activador, de tal manera que podamos acercarnos a esa combinación de criticidad y solidaridad que vincula nuestros afectos” (p. 187). La fuerza activadora es clave en la comprensión performativa de la inclusión.

El espacio intersticial del concepto - unidad relacional conformado por diversos pliegues, designa un sistema de implicación mutua, asume una conjunción compleja, esta implicación permite desnaturalizar el término y con ello, ir resolviendo el problema morfológico que la atraviesa. En efecto, cada categoría posee una especificidad histórica, crea formas de rearticulación y replanteamiento- ensambla una zona de contacto, forja una conjunción que actúa como enlace no sólo de dos palabras, sino de un conjunto de elementos de diversa naturaleza implicados en la estructuración teórica de la educación inclusiva. La forma conjuntiva forja una singular modalidad de nexo. ¿Qué naturaleza posee este nexo? Su función consiste en establecer relaciones, en ella, se suman los significados de ambas, resultando algo nuevo en el marco de una relación equitativa. Se establece una condición analítica de carácter operativa. Lo copulativo posee un valor aditivo, relacional y de intermediación.

Me interesa examinar la fuerza teórica y política que reside en la palabra inclusiva. Manifiesta la acción de una educación políticamente comprometida con las demandas de su tiempo -historicidad del presente (saber en permanente movimiento), diferenciada desde el presentismo- ¿dónde está el nuevo tipo de educación al que nos conduce?, ¿a qué le confiere forma?, ¿a qué interpela a los espectadores, ¿los moviliza a qué? Por un lado, sugiere un aprender a ver, ¿cómo nos situamos ante el deseo de la inclusión? La emancipación del espectador es entonces la afirmación de su capacidad de ver lo que él ve y de saber qué pensar y qué hacer con ello. La inclusión favorece la capacidad para repensar las posiciones políticas. Se interesa describir qué es lo que puede hacer la inclusión -su sentido activador, escultórico y movilizador de la realidad-. ¿Qué fronteras moviliza realmente este discurso y cómo esto incide en la formación de los educadores? La condición de audibilidad, activadora y 
escultórica lleva a sus interlocutores a pensar sobre la transformación y la negatividad. Se convierte en una apelación, en una provocación, en un compromiso con el conflicto político del mundo actual.

El carácter conjuntivo que designa el sintagma educación inclusiva configura una compleja forma copulativa y conjuntiva, que términos analíticos pueden ser concebidos a través de la metáfora de la y-cidad, es decir, un espacio intermedio en el que se conectan diversas clases de preocupaciones intelectuales. La 'y-cidad' no es solamente un sistema de relaciones sino de implicaciones profundas en la construcción del conocimiento, la unión refleja un plan de composición, es un campo de experimentación conceptual. La 'y-cidad' define su funcionamiento a través del principio de complementariedad, estrategia que tiende a la unión de elementos de naturaleza heterogénea y contraria, b) la infinidad de elementos entre campos, conceptos, teorías, disciplinas en contradicción, c) la 'y-cidad' opera a través de la metáfora del tercer incluido -la lógica de ' $y$ ' o 'e', mecanismo de interrelaciones e integración de diversas herramientas epistemológicas. Instala una lógica que a partir de la contribución de Lupasco, designa un estado dinámico intermedio y en potencia -lo no manifestado- y actualización -lo manifestado-. La 'y-cidad' como espacio intermedio o zona de intermediación epistemológica, opera en términos de un campo de fuerza conciliador de una amplia multiplicidad de elementos, es un lugar en permanente interacción y mutación.

La 'y-cidad' es clave para comprender el espacio de diáspora, desborda las programaticidades convencionales, explicita un sistema recognoscitivo, opera como un espacio de intersticialidad. El campo epistemológico de la educación inclusiva es un terreno compuesto por múltiples conexiones -principio de heterogénesis-, lo intermedio del sintagma es lo que establece conexiones singulares, forma una particular conjunción, articulada a través de la metáfora de 'síntesis-disyuntiva'. En efecto,

[...] para hacer conexiones uno no necesita conocimiento, certeza, o incluso ontología, sino más bien una confianza que algo puede salir, aunque uno todavía no está completamente seguro qué, Hume sustituyó a la certeza cartesiana una probabilidad de creencia, pero Deleuze empuja la cuestión de la creencia en esa zona de una "posibilidad improbable" que ningún lanzamiento de dados puede abolir (RACHJMAN, 2000, p. 7).

En este sentido, retomo la metáfora de la 'y-cidad', puesto que facilita la propensión al conjunto de procesos que legitiman su acción en el mundo, así como, el conjunto de interconexiones que delimitan lo que realmente es. La 'y-cidad' de la educación inclusiva 
opera en términos de una singular y compleja forma conjuntiva de carácter disyuntiva, cuyas líneas de segmentariedad, estratificación y fuga, operan en términos de reciprocidades multiniveles. Su dimensión viajera precedida por la idea de campo y objeto en permanente movimiento y acción relacional, indica que, "las teorías pueden perder su originalidad y posición crítica a medida que viajan de un dominio a otro" (HILL COLLINS, 2015, p. 12). El viaje como metáfora clave en la construcción del conocimiento impone un conjunto de tecnologías de rearticulación de sus objetos, saberes y conceptos. Sus usuarios son siempre heterogéneos, marcados por diversas referencias geopolíticas, demostrando una preocupación endémica al quehacer educativo.

\section{REFERENCIAS}

BAL, Mieke. El esencialismo visual y el objeto de los Estudios Visuales. Estudios visuales: Ensayo, teoría y crítica de la cultura visual y el arte contemporáneo, n. 2, p. 11-50, 2004.

BAL, Mieke. Y-cidad: los múltiples sentidos de 'y'. Versants, v. 65, n. 3, p. 187-207, 2018.

BURMAN, Erika. Child as method: implications for decolonising educational research.

International Studies in the Sociology of Education, v. 28, n. 3), p. 1-23, 2017. Recuperado de: https://www.tandfonline.com/doi/abs/10.1080/09620214.2017.1412266. Acceso en: 12 fev. 2020.

COȘOBEA, Timeea. Asia as method. Now and then: Investigating the Critical concept of the Inter-Asia referencing, 2017. Recuperado de:

https://pdfs.semanticscholar.org/7e6b/7bcd7c4219ed381ec130e7afc67c63cbcd50.pdf. Acceso en: 12 fev. 2020.

CHEN, Kuan-hsing. Asia as method: towards deimperialization. Durham: Duke University Press, 2010.

CHEN, Kuan-hsing. Takeuchi Yoshimi's 1960 'Asia as method' lecture. Inter-Asia Cultural Studies, v. 13, n. 2, p. 317-324, 2012.

FELMAN, Shoshana. To Open the Question, Yale French Studies: Literature and Psychoanalysis. The Question of Reading: Otherwise, n. 55/56, p. 5-10, 1977.

FERNÁNDEZ, Aurora. Editorial. Usos performativos de las imágenes. Revista Re-visiones, v. 2, n. 2, p. 1-5, 2012.

GAZTAMBIDE-FERNÁNDEZ, Rubén, THIESSEN, Dennis. Fomenting flows and internationalizing curriculum studies. Curriculum Inquiry, v. 42, n. 1, p. 1-11, 2012.

GENETE, Gerard. Palimpsestos. La literatura en segundo grado. Madrid: Taurus, 1989.

HALL, Stuart. La cultura y el poder. Buenos Aires: Amorrortu, 2011. 
HILL COLLINS, Patricia. Intersectionality. As critical social theory. Duke: Duke University Press, 2015.

MEZZADRA, Sandro; NEILSON, Brett. Border as Method. Durham: Duke University Press, 2012.

OCAMPO, Aldo. Contornos teóricos de la educación inclusiva. Revista Boletín Redipe, v. 8 n. 3, p. 66-95, 2019.

OLIVEIRA, Ana. Lo intermedio como espacio. Lo intersticial, lo fronterizo y lo impreciso en la arquitectura contemporánea. Madrid: UPM, 2016.

RACHJMAN, John. Constructions. New York: MIT Press Ltd, 2004.

WILliAMS, Raymond. Palabras Clave. Nueva Visión, Buenos Aires, 2003.

SMITH, Linda Tuhiwai. A descolonizar las metodologías. Investigación y pueblos indígenas. Santiago: LOM, 1999.

\section{Cómo referenciar este artículo}

OCAMPO GONZÁLEZ, Aldo. La educación inclusiva como estrategia analítica. Revista Ibero-Americana de Estudos em Educação, Araraquara, v. 15, n. 1, p. 2-26, jan./mar. 2020. e-ISSN: 1982-5587. DOI: https://doi.org/10.21723/riaee.v15i1.13302

Remitido en: 10/06/2019

Aprobado en: 23/11/2019

Publicado en: 02/01/2020 